\title{
SMC composites waste management as reinforcing fillers in polypropylene by combination of mechanical and chemical recycling processes
}

\author{
DIDIER PERRIN, CÉLINE GUILLERMAIN, ANNE BERGERET, \\ JOSÉ-MARIE LOPEZ-CUESTA*, GILLES TERSAC \\ Ecole des Mines d'Alès, France
}

\begin{abstract}
A new process of management of waste of composite materials from Sheet Moulding Compounds (SMC), as reinforcing fillers for thermoplastic materials, including both mechanical and chemical processes is proposed in this paper. Communited SMC being composed of coated glass fibres intimately mixed with calcium carbonate powder, their reinforcing power is low. First, the fibrous part was increased by partial dissolution of calcium carbonate present in the crushed products SMC. Second, a process of partial solvolysis was developed aiming at strong increasing the interfacial mechanical properties by functionalising of SMC load incorporated into polypropylene/grafted maleic anhydride polypropylene (PP/PP $\left.{ }_{\text {gma }}\right)$. At this effect, we investigated a treatment with a hot triamine (diethylenetriamine, DETA) in order to create a functionalisation, after scission of the bond ester of unsaturated polyester, as bridging amino-succinimide. The effect of this recycling way by partial solvolysis was checked from the mechanical properties of the resulting reinforced PP/PP ${ }_{\text {gma }}$ material: Although a lower of Young modulus, better yield stress and especially resilience were observed.
\end{abstract}

\section{Introduction}

Sheet Moulding Compounds (SMC) are some of the most largely thermosetting materials used in the composites industry. Their interest is mainly due to their high strength-to-weight ratio, low cost, corrosion resistance and metallic appearance when painted. They associate 25-50 $\mathrm{mm}$ chopped glass fibres (GF) and a blend of unsaturated polyester diluted in styrene, calcium carbonate used as filler and low profile additives (mainly polymers), a curing catalytic system and among other additives, a thickener and a releasing agent.

However, major obstacles to the development of the use of SMC, including in its main domains of applications such as transportation, are the heterogeneity of composition and the difficulty of recycling due to its thermoset character and consequently its infusibility and insolubility.

Since non-manageable residues or poor value decomposition products are the final outputs of management methods, only mechanical recycling may lead to fillers which can be used similarly as reinforcing fibres, provided a good optimization of the process has been achieved, in order to avoid dramatic degradation of the reinforcing filler.

Mechanical recycling has now reached industrial applications [1]. This technique is generally based on granulation and controlled comminution of the composite material, followed by a sieving process. The obtained fractions (fibres, powder) are used for a variety of applications, depending on the particle size, morphology and glass fibre content. For example, medium size fibres (about $1 \mathrm{~mm}$ ) are recyclable in thermoplastics [2-5]. A part of the present work is focused on this last application. A specific strategy is developed in order to obtain ground SMC fractions with optimised characteristics for their introduction as reinforcing fillers in thermoplastics. The originality of the process consists in association of shredding and removal of a calcium carbonate fraction by dissolution in an acid solution.

A complementary way to mechanical recycling may consist in a chemical treatment of the composite material. Chemical recycling approaches by solvolysis can be applied to the raw composite material or to the fractions 
issued from mechanical recycling. Very long and clean fibres were obtained by Winter et al. using solvolysis [6]. Nevertheless, this process lead to a too low density for the fibre bundle, to allow simply a re-incorporation in a new SMC manufacture. Moreover, solvolysis experiments made in our laboratory showed that the reactivity of glycols, diacids and bisphenols [7] is too low to enable a total depolymerisation of the matrix, whereas amine compounds at boiling temperature allowed the modification of the composite with dissolution of the matrix, leading to GF bundles and $\mathrm{CaCO}_{3}$ powder almost free of organic contamination. However, the composite dismantlement needs a $10 \mathrm{~h}$ treatment of SMC with diamines at $200^{\circ} \mathrm{C}$. Finally, the re-employment of fibres, for reinforcement of thermoplastics or thermosets, needs to be evaluated.

Thus, another recycling way could be, not a solvolysis in the target to recover simultaneously the fibres, fillers and the organic part as valuable depolymerisation products, but a partial solvolysis limited at the surface of the particles $[7,8]$.

Consequently, the originality of this research was to associate a partial solvolysis and a controlled mechanical recycling of SMC waste sheets, with a partial removing of calcium carbonate. This was expected to result in an increase of the chemical reactivity for the selected composite waste fractions, leading to a more convenient process in order to obtain reinforcing fractions. In addition, the chemical reactivity of this reinforcing filler was expected to allow a better coupling with a polymer matrix than no-chemically treated fractions, by using an interfacial coupling agent.

\section{Methodology}

\subsection{Processing purpose from $S M C$ to $S M C^{\text {mod }}$}

The proposed treatment of SMC waste is based on a two steps approach that aims to obtain the longest fibres and the highest fibre content in the final product (about 40 wt.\%). An initial shredding step with a slight crushing (allowing to liberate the fibres from the embedding polyester matrix) is followed by a selective dissolution of calcium carbonate in an acid bath (in order to increase significantly the amount of fibres) [8].

The optimization of this process was made by a two steps optimal experimental design approach, followed by a validation of capability by Statistical Process Control [8]. Process effectiveness, distribution of fibres length and glass fibre content in the final SMC ground fraction called $\mathrm{SMC}^{\mathrm{mod}}$ are considered.

\subsection{The aim and design of the $\mathrm{SMC}^{\mathrm{mod}}$ partial solvolysis}

Partial solvolysis process is based on the selective degradation of the unsaturated polyester (UP) polymer network by reaction of the ester linkages with an appropriate nucleophile. Several studies on solvolysis of UP have already been carried out last few years.
Tesoro [9] has described investigations focused on the neutral hydrolysis of soluble well-characterized unsaturated polyester. The optimum solvolysis conditions in terms of product yields were $260^{\circ} \mathrm{C} / 6 \mathrm{~h}$ in mixed solvents systems as butanone/water $1 / 5(\mathrm{v} / \mathrm{v})$ or butanone/propan2 -one/water $1 / 0.25 / 1(\mathrm{v} / \mathrm{v})$. These solvents combinations allowed a total liquefaction and an easy separation of the soluble products: The resulting oligomer may be used as curing agent and/or co-reactant for epoxy resin in the development of coatings or for UP resins.

More recently, Kubota [10] worked on the solvolysis of UP resin waste using dicarboxylic acid or diamine to obtain resin raw material. The crushed UP were heated at high temperature $\left(250-280^{\circ} \mathrm{C}\right)$ in presence of a basic catalyst $(\mathrm{NaOH})$ under a nitrogen atmosphere and under pressure with a large excess of solvent (weight ratio about 10/1). Several solvents such as adipic acid (AdA), diethylenetriamine (DETA), hydroquinone (HQ) or ethanolamine (MEA) allowed the complete digestion of the UP resin after a 3-5 h reaction. UP resin could be re-synthesised with the obtained resin raw material.

Several publications present studies on solvolysis of SMC with different reagent solvents.

Tufts et al. [11] studied the glycolysis with diethylene glycol (DEG) or dipropylene glycol (DPG) of SMC particles and a total solvolysis was obtained with basic catalysts such as sodium methoxide or potassium hydroxide after $2.5 \mathrm{~h}$ at $245^{\circ} \mathrm{C}$.

Winter et al. [6] have described the selective degradation of SMC in presence of water, ethanol, potassium hydroxide and various amines. They showed that the unsaturated polyester polymer network obtained after SMC chips curing could be uncrosslinked in the presence of ethanolamine (MEA) at $180^{\circ} \mathrm{C}$ for a $48 \mathrm{~h}$ treatment. Treatment of SMC with MEA leads to three fractions: GF, filler, and a methanol-soluble polymer containing hydroxyl groups.

According to Tai [12], xylylenediamine (XDA) seems to be a promising reactant for the solvolysis of $1 \mathrm{~mm}$ sized SMC particles. The total degradation of the composite was achieved at $170^{\circ} \mathrm{C}$ after $2 \mathrm{~h}$.

Until now, two patents recommended a partial solvolysis limited to a chemical attack of the composite surface. The aim was to allow the incorporation of the functionalised particles (pulverised or shredded beads) in a epoxy resin compound by amine [12] and phenol with p-toluenesulphonic acid treatment [13].

\section{Experimental}

\subsection{Materials}

SMC composite panels $\left(500 \times 500 \times 4 \mathrm{~mm}^{3}\right)$ provided by Saint Gobain Vetrotex (Chambéry, France) were moulded. They contained 23 wt. $\%$ of randomly oriented short E-glass fibres (standard length $25 \mathrm{~mm}$ ), 55 wt. $\%$ $\mathrm{CaCO}_{3}, 22$ wt.\% polyester resin and correspond to the composition of SMC production waste. Commercial short 


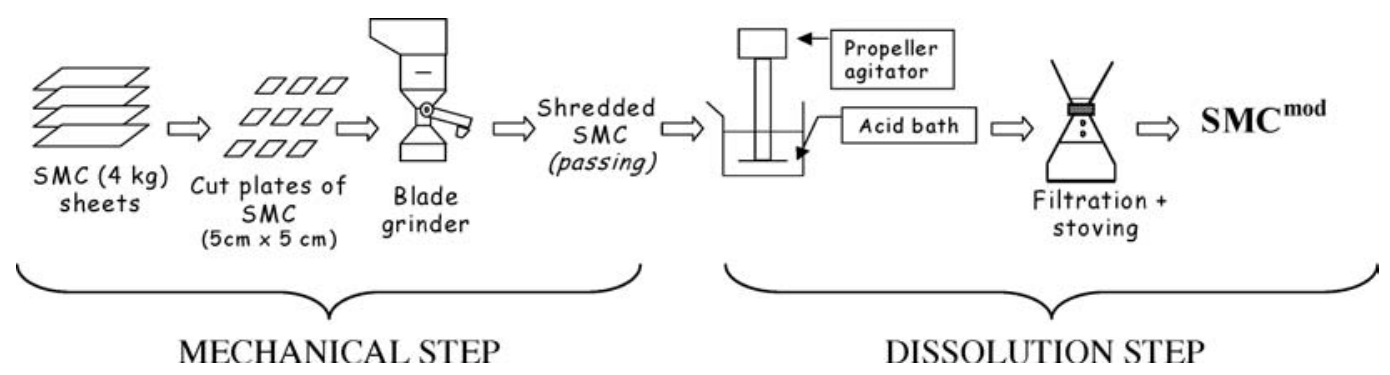

Figure $1 \mathrm{SMC}^{\mathrm{mod}}$ design process.

virgin glass fibres of $4.5 \mathrm{~mm}$ length and $15 \mu \mathrm{m}$ diameter, with a surface treatment compatible for polypropylene were also supplied by Saint Gobain Vetrotex. Postconsumer SMC ground fraction (T401), optimised for recycling as thermoplastic filler/reinforcement, was supplied by MCR (Tournon, France) and also used as a reference.

A blend of polypropylene homopolymer (84 wt.\%) and (propylene-co-ethylene) 50/50 wt.\% copolymer (16 wt.\%) used for composite manufacturing was supplied by Appryl $\left(3150 \mathrm{MN} 5\left(T_{\mathrm{m}}=169^{\circ} \mathrm{C}\right.\right.$ and $\left.T_{\mathrm{g}}=10^{\circ} \mathrm{C}\right)$ ). Orevac CA100 polypropylene, grafted with $0.4 \%$ of maleic anhydride $\left(\mathrm{PP}_{\mathrm{gma}}\right)\left(T_{\mathrm{m}}=148^{\circ} \mathrm{C}\right.$ and $T_{\mathrm{g}}$ $=19^{\circ} \mathrm{C}$ ), was supplied by Atofina and used as interfacial agent.

Diethylenetriamine (DETA) was chosen as solvent reagent for its high boiling temperature $\left(205-207^{\circ} \mathrm{C}\right)$. Its density and melting point are respectively 0.955 and $39^{\circ} \mathrm{C}$.

\subsection{SMC modification}

SMC panels were first cut and conditioned into smaller parts $\left(50 \times 50 \times 4 \mathrm{~mm}^{3}\right)$. The modified filler $\mathrm{SMC}^{\text {mod }}$ was obtained from a mixed process consisting in two steps.

SMC pieces were first ground during $25 \mathrm{~min}$ at a $1500 \mathrm{rpm}$ using a Rotoplex-Alpine Rotary Cutter Mill, with a grid of $12 \mathrm{~mm}$ [17]. The residence time was less than $2 \mathrm{~s}$. Such conditions allowed to obtain $2-10 \mathrm{~mm}$ glass fibres.

The passing ground fraction was then introduced in a $\mathrm{H}_{3} \mathrm{PO}_{4}$ buffer solution with strong agitation in order to promote a partial dissolution of $\mathrm{CaCO}_{3}$. The objective of this second treatment was to obtain the highest fibre fraction in the final recycled fraction (40 to $50 \% \mathrm{w} / \mathrm{w}$ ). Two experimental designs were used to optimize the parameters of this second part of the process: $100 \mathrm{~g}$ of shredded SMC was dissolved at room temperature into a $\mathrm{H}_{3} \mathrm{PO}_{4}$ buffer solution $\left(0.3 \mathrm{M}, \mathrm{pH} 1.9,5 \cdot 10^{-3} \mathrm{~m}^{3}\right)$. The stirring time and the rotative speed of the propeller agitator were respectively of $60 \mathrm{~min}$ and $1100 \mathrm{rpm}$. The partially dissolved fraction was then filtered and dried for $3 \mathrm{~h}$ at $80^{\circ} \mathrm{C}$. The whole process leading to $\mathrm{SMC}^{\text {mod }}$ is described on Fig. 1 [8].

Solvolysis reactions were then conducted in a $6 \mathrm{~L}$ threeneck reactor equipped with a reflux condenser, a nitrogen inlet and a mechanical PTFE blade stirrer. $385 \mathrm{~g}$ of shredded SMC ${ }^{\text {mod }}$ were first mixed with $3.5 \cdot 10^{-3} \mathrm{~m}^{3}$ of DETA during $10 \mathrm{~min}$. Stopping the stirring after the moistening of SMC ${ }^{\text {mod }}$ allowed to avoid the formation of glass fibres bundles (Fig. 2b). Then the mixture was heated under nitrogen flow until $200^{\circ} \mathrm{C}$. After $3 \mathrm{~h}$, the reacting mass was cooled and the product was filtered. The remaining solid presented a heterogeneous aspect composed of white powder and little white patches bonded to fibre and of free white powder (Fig. 2).

\subsection{Characterization of modified SMC and composites}

The different fractions $\mathrm{SMC}^{\text {mod }}$ and $\mathrm{SMC}_{\text {solv }}^{\text {mod }}$ were analysed using a FTIR Perkin Elmer spectrometer by ATR technique (Attenuated Total Reflectance).
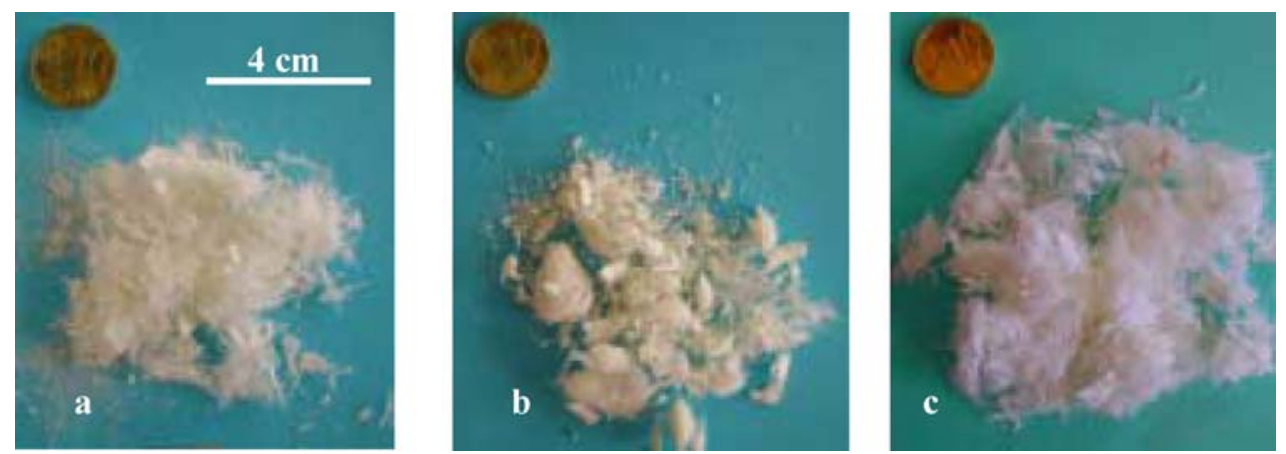

Figure 2 Appearance of the shredded $\mathrm{SMC}^{\mathrm{mod}}$ before partial solvolysis (a) and after a $3 \mathrm{~h}$ solvolysis et $200^{\circ} \mathrm{C}$ with continuous stirring (b) or without stirring after moistening (c). 
The organic fraction was first measured by weight loss after pyrolysis at $625^{\circ} \mathrm{C}$ for $180 \mathrm{~min} . \mathrm{CaCO}_{3}$ amount was then measured by calcimetry. This technique is based on the measurement of $\mathrm{CO}_{2}$ volume evolved from the reaction of $\mathrm{CaCO}_{3}$ with $\mathrm{HCl}$ in standard temperature and pressure conditions, leading to the amount of calcium carbonate present in the filler:

$$
\% \mathrm{CaCO}_{3}=\frac{100 \cdot M_{\mathrm{CaCO}_{3}} \cdot V_{\mathrm{CO}_{2}}}{24040 \cdot m_{\mathrm{SMC}}}
$$

where $\mathrm{m}_{\mathrm{SMC}}$ is the $\mathrm{SMC}$ amount, $\mathrm{V}_{\mathrm{CO}_{2}}$ the $\mathrm{CO}_{2}$ volume evolved and $M_{\mathrm{CaCO}_{3}}$ the molar mass of $\mathrm{CaCO}_{3}$. Finally, the remaining glass fibre fraction was determined by difference.

Fibre length distribution was determined both before and after composite injection processing for all the recycled fractions (SMC ${ }^{\mathrm{mod}}, \mathrm{SMC}_{\text {solv }}^{\text {mod }}$ and $\left.\mathrm{T} 401\right)$ and for the commercial short glass fibres after extrusion. The whole sample preparation method has been described on a previous paper [7]. Fibres length distribution was obtained by a semi-automatic images analysis system based on Optimas software. Number average length $L_{n}$, length average length $L_{1}$ and dispersity $D\left(\left(L_{1}-L_{\mathrm{n}}\right) / L_{\mathrm{n}}\right)$ were then calculated using a gaussian model distribution.

High-resolution ${ }^{13} \mathrm{C}$ NMR spectra were obtained at two different principal fields $(9.4 \mathrm{~T}-400 \mathrm{MHz}$ and $17.6 \mathrm{~T}-$ $750 \mathrm{MHz}$ ) on Bruker ADVANCE instruments equipped with high speed MAS probeheads (spinning rates of 10 to $14 \mathrm{kHz}$, aluminium-free zirconia rotors of $2.5 \mathrm{~mm}$ diameter) from Orleans (France). Typical acquisition conditions were: $50-60 \mathrm{kHz}$ radio frequency field for ${ }^{1} \mathrm{H}$ during excitation, CP-MAS and decoupling; 1-s recycle delay with pre-saturation before acquisition, contact times varying from $250 \mu \mathrm{m}$ up to $3 \mathrm{~ms}$. Spectra were referenced relative to TMS at $0 \mathrm{ppm}$ for ${ }^{13} \mathrm{C}$. All NMR samples were prepared by powdering the SMC material at the granulometry of $200 \mu \mathrm{m}$ diameter size.
All the fillers were incorporated into polymer using a Clextral BC 21 twin screw extruder (barrel temperature of $200^{\circ} \mathrm{C}$, screws speed of $350 \mathrm{~min}^{-1}$ ). The PP matrix was blended with $5 \% \mathrm{w} / \mathrm{w}$ of a polypropylene grafted maleic anhydride to ensure a good adhesion between matrix and fillers, except a reference composite with virgin glass fibers in which only the PP matrix was present. Injection moulding of specimens was performed using a $95 \mathrm{t}$ SANDRETTO AT. Tensile and Charpy impact tests were performed $72 \mathrm{~h}$ after injection moulding. Tensile tests (Young's modulus and yield stress) were carried on using a ZWICK Z010 apparatus according to ISO 527-2 standard. Charpy tests were carried out on unnotched specimens using a ZWICK 5101 (4 J) device according to ISO 179 standard.

\section{Results and discussion}

The amount of $\mathrm{SMC}^{\mathrm{mod}}$ and $\mathrm{SMC}_{\text {solv }}^{\text {mod }}$ fillers was fixed at $47 \%$ and $42 \% \mathrm{w} / \mathrm{w}$ respectively to obtain about $20 \% \mathrm{w} / \mathrm{w}$ glass fibres content in all the composites. A PP composite containing $20 \% \mathrm{w} / \mathrm{w}$ of commercial glass fibres was used as reference. The T401 composite is prepared similarly as $\mathrm{SMC}^{\text {mod }}$. The PP composites are referenced in Table I.

\subsection{Characterisation of the $\mathrm{SMC}^{\text {mod }}$ fraction}

The aspect after shredding of the ground SMC before dissolution step is presented on Fig. 3. Observation of

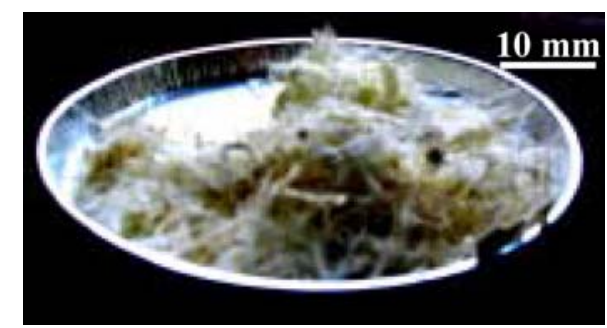

Figure 3 Appearance of shredded SMC.

TAB LE I Compositions of the different composites

\begin{tabular}{lllll}
\hline $\begin{array}{l}\text { Composites based on } \\
\mathrm{PP}_{\mathrm{PP}}{ }_{\text {gma }}{ }^{*}\end{array}$ & $\begin{array}{l}\text { Commercial glass } \\
\text { fibres(1) }\end{array}$ & $\begin{array}{l}\text { Mixed process } \\
\left(\mathrm{SMC}^{\mathrm{mod}}\right)(2)\end{array}$ & $\begin{array}{l}\text { Solvolysis process } \\
\left(\mathrm{SMC}_{\text {solv }}^{\text {mod }}\right)(3)\end{array}$ & $\begin{array}{l}\text { Commercial ground } \\
\mathrm{T} 401(4)\end{array}$ \\
\hline $\begin{array}{l}\text { Fillers amount in composite } \\
\quad(\text { wt.\%) }\end{array}$ & 20 & 47 & 42 & 42 \\
\begin{tabular}{l} 
Overall fibre amount (wt.\%) \\
\hline
\end{tabular} & 20 & 20 & 20 & 20 \\
\hline
\end{tabular}

*Except commercial glass fibres where these one were already coated by $\mathrm{PP}_{\text {gma. }}$, (1) PP20GF $\mathrm{GP}_{\mathrm{PP}}$, (2) $\mathrm{PP} 20 \mathrm{GF}_{\mathrm{SMC}}^{\mathrm{mod}} 5 \mathrm{PP}_{\mathrm{gma}}$, (3) $\mathrm{PP}_{20 \mathrm{GF}}^{\mathrm{mod}}$ solv5 $5 \mathrm{PP}_{\mathrm{gma}}$, (4) PP20GF $_{\text {T401 }}$ 5PPgma

TAB LE II SMC composition and efficiency according to the recycling process

\begin{tabular}{llllll}
\hline Composition (w\%) & Initial SMC & Pure grinding (first step) & SMC $^{\text {mod }}$ & SMC $_{\text {solv }}^{\text {mod }}$ & $\begin{array}{l}\text { T401 filler } \\
\text { (commercial process) }\end{array}$ \\
\hline Unsaturated Polyester & $26.0 \pm 2.5$ & $22.7 \pm 2.5$ & $31.8 \pm 2.5$ & $23.7 \pm 2.5$ & $22.0 \pm 2.5$ \\
Calcium carbonate & $52.0 \pm 2.5$ & $55.0 \pm 2.5$ & $25.6 \pm 2.5$ & $28.3 \pm 2.5$ & $29.0 \pm 2.5$ \\
Glass fibre & $22.0 \pm 2.5$ & $22.3 \pm 2.5$ & $42.6 \pm 2.5$ & $49.0 \pm 2.5$ & $42.0 \pm 2.5$ \\
\hline
\end{tabular}



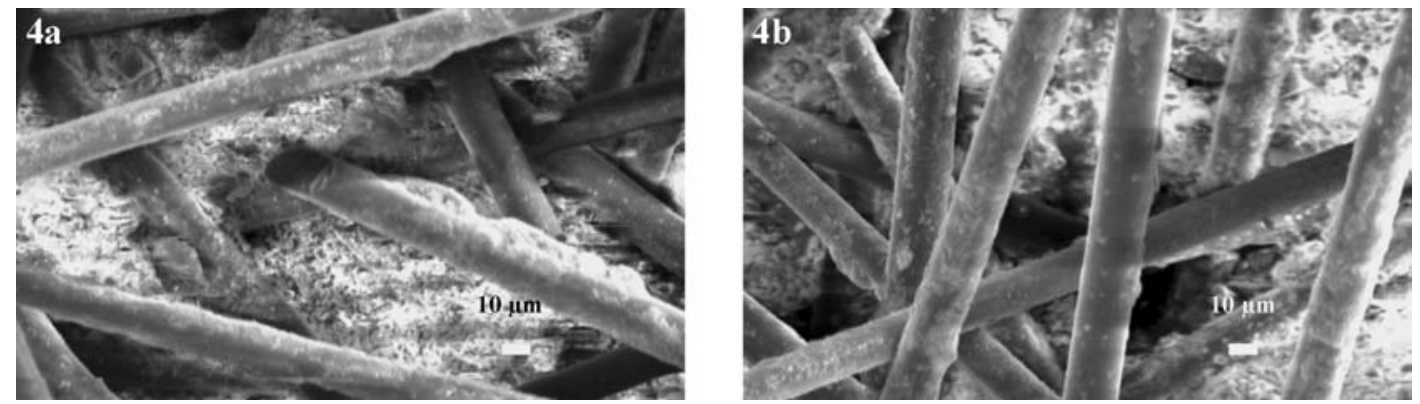

Figure 4 SEM images $\times 100$ of passing through ground (a) SMC and (b) SMC ${ }^{\text {mod }}$.

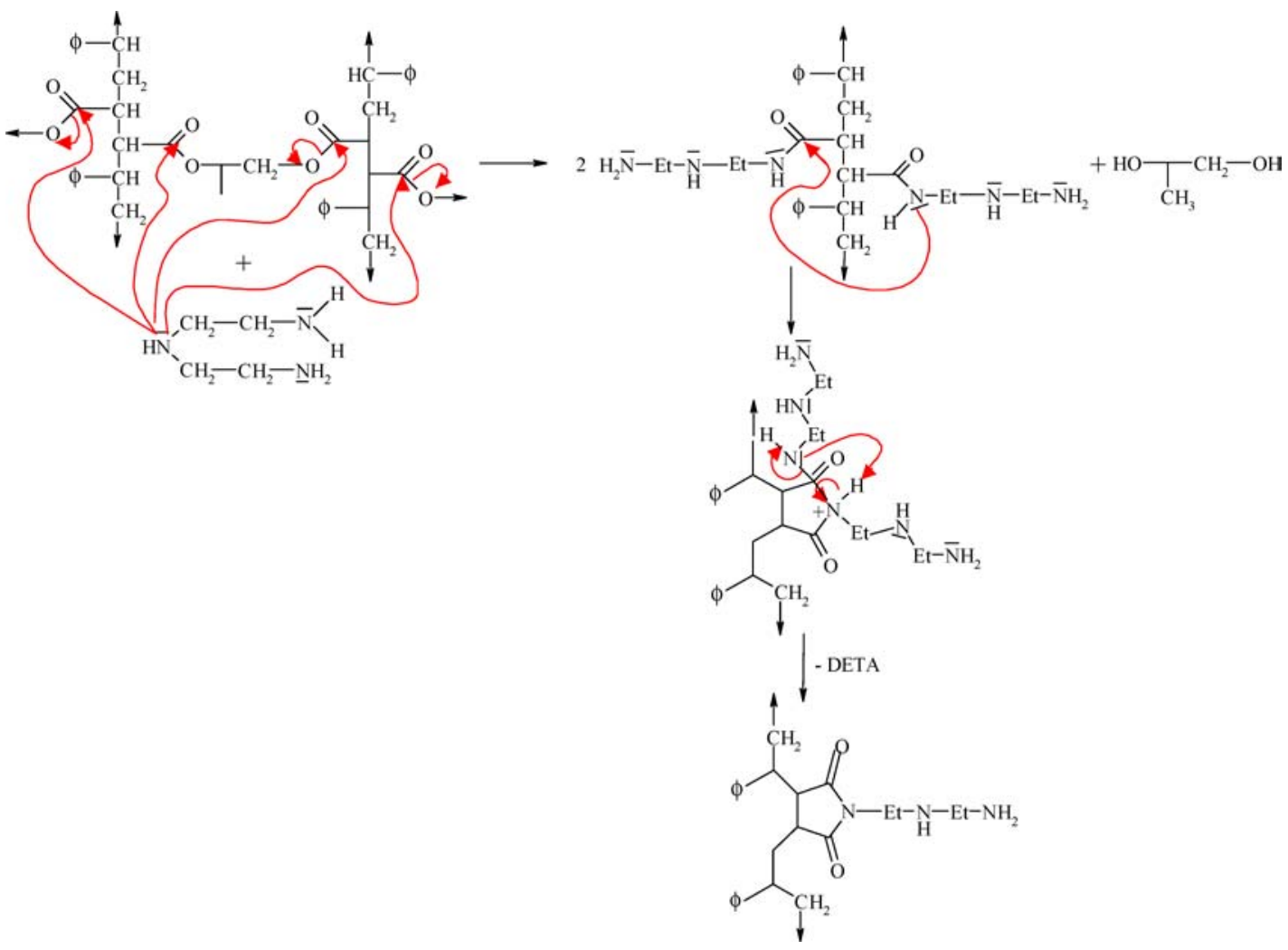

Scheme 1 Proposed mechanism for the formation of succinimide derivated from DETA by reaction between UP and DETA.

comminuted recyclate reveals that the recycled particulates are covered by a layer of fine powder, bonded to their surface through electrostatic forces.

The SEM observations performed on SMC and $\mathrm{SMC}^{\text {mod }}$ fractions are shown on Fig. 4. It can be observed that both fractions are similar and, that most of the glass fibres present have been well separated from the polyester matrix. Nevertheless, this observation reveals also that the recovered glass fractions are heterogeneous since fibres, residual polymer resin and calcium carbonate remain present, either as free powder or in the form of a resin sheath surrounding the fibres.

The compositions of initial SMC and SMC ${ }^{\text {mod }}$ fractions are detailed in Table II The high glass fibre content observed for T401 (42\%) is ascribed to the fact that this fraction was a mixture of pure glass fibre waste and SMC recycled fractions and hence, the fibrous fraction is initially very rich in glass fibres.

SMC $^{\text {mod }}$ compared to initial SMC, presents a lower polyester and calcium carbonate fraction. If the UP composition of $\mathrm{SMC}^{\text {mod }}$ and $\mathrm{SMC}_{\text {solv }}^{\text {mod }}$ are compared, an important decrease in the unsaturated polyester content $(-25 \%)$ can be noticed, corresponding to the chemical attack of the $\mathrm{SMC}^{\text {mod }}$ surface during the partial solvolysis.

The average length of glass fibres is presented on Table III SMC ${ }^{\text {mod }}$ clearly shows higher fibre length than T401. The fibre length is moreover too high to be analysed quantitatively by our image analysis procedure [8]. It could be noticed that this initial fibre length is comparable to that of the commercially available short glass fibres used for reinforced thermoplastics. 


\begin{tabular}{lllll}
\hline & Commercial glass fibres & Initial SMC & Mixed process (SMC ${ }^{\text {mod }}$ ) & $\begin{array}{l}\text { T401 filler (commercial } \\
\text { process) }\end{array}$ \\
\hline Average length $(\mathrm{mm})$ & $4.5^{* *}$ & $25-50^{* *}$ & $2-10^{*}$ & $0.7^{* * *}$
\end{tabular}

*Manually determined.

** Commercial data.

*** Semi-automatically determined by image analysis according to the above described process.

\subsection{Characterisation of the solvolysed SMC ${ }^{\text {mod }}$ fraction}

As only a partial chemical attack of the $\mathrm{SMC}^{\text {mod }}$ is wanted and not a complete degradation of the organic matrix, less severe experimental conditions than these used for the total degradation of the composite have been selected [7]. Consequently, the partial solvolysis reaction was carried out at $200^{\circ} \mathrm{C}$ (the boiling point of DETA is about $200^{\circ} \mathrm{C}$ ) for $3 \mathrm{~h}$ instead of $10 \mathrm{~h}$ [7], which is the recommended temperature for a total modification of the organic matrix.

The chemical mechanism of the DETA on the UP matrix, that can be proposed, is presented on Scheme 1 .

Concerning the FTIR analysis, all the fractions of the heterogeneous collected product (GF covered with white powder, GF with little white patches and white powder) have been analysed by FTIR spectroscopy.

Fig. 5 presents the ATR FTIR spectra of the SMC ${ }^{\bmod }$ before and after partial solvolysis by DETA during $3 \mathrm{~h}$ at $200^{\circ} \mathrm{C}$.

Spectra indicate peaks of styrene (St) moieties at 1600, 1490, 1160, 1030, 905 and $698 \mathrm{~cm}^{-1}$. Moreover, a decrease of the ester peak intensity located at $1730 \mathrm{~cm}^{-1}$ is observed as well as the formation of two new peaks at $1769 \mathrm{~cm}^{-1}$ (low intensity) and $1698 \mathrm{~cm}^{-1}$ (high intensity), both related to imide function and another at $1675 \mathrm{~cm}^{-1}$ related to imidazoline moieties [19]. The presence of these

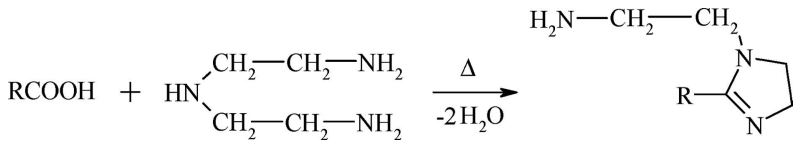

Scheme 2 Formation of imidazoline from reaction between DETA and fatty acid $[16,20]$

imide functions could correspond to the formation of succinimide derivated from DETA by reaction between UP and DETA according to Scheme 1.

This last result is in agreement with Winter et al. works [6] on the UP solvolysis by MEA that reacts by its amino groups with the diamine derivated from the succinic acid.

Furthermore, according to other authors [14, 15], DETA reacts with fatty acids to form also imidazoline at high temperatures $[16,20]\left(280-300^{\circ} \mathrm{C}\right)($ Scheme 2$)$.

A secondary reaction between ester and DETA, which could be another way to form imidazoline, may occur. A mechanism for this reaction is proposed on Scheme 3.

As regards the CP/MAS ${ }^{13} \mathrm{C}-\mathrm{NMR}$ spectra of $\mathrm{SMC}^{\text {mod }}$ and $\mathrm{SMC}_{\text {solv }}^{\text {mod }}$ on Fig. 6, one might suppose that thermoset composites and especially solvolysis or pyrolysis of thermosets would produce a mixture of degradation products so complex that NMR spectroscopy could provide no useful information without prior separation of the individual components. First, the volatile low-molecular-weight

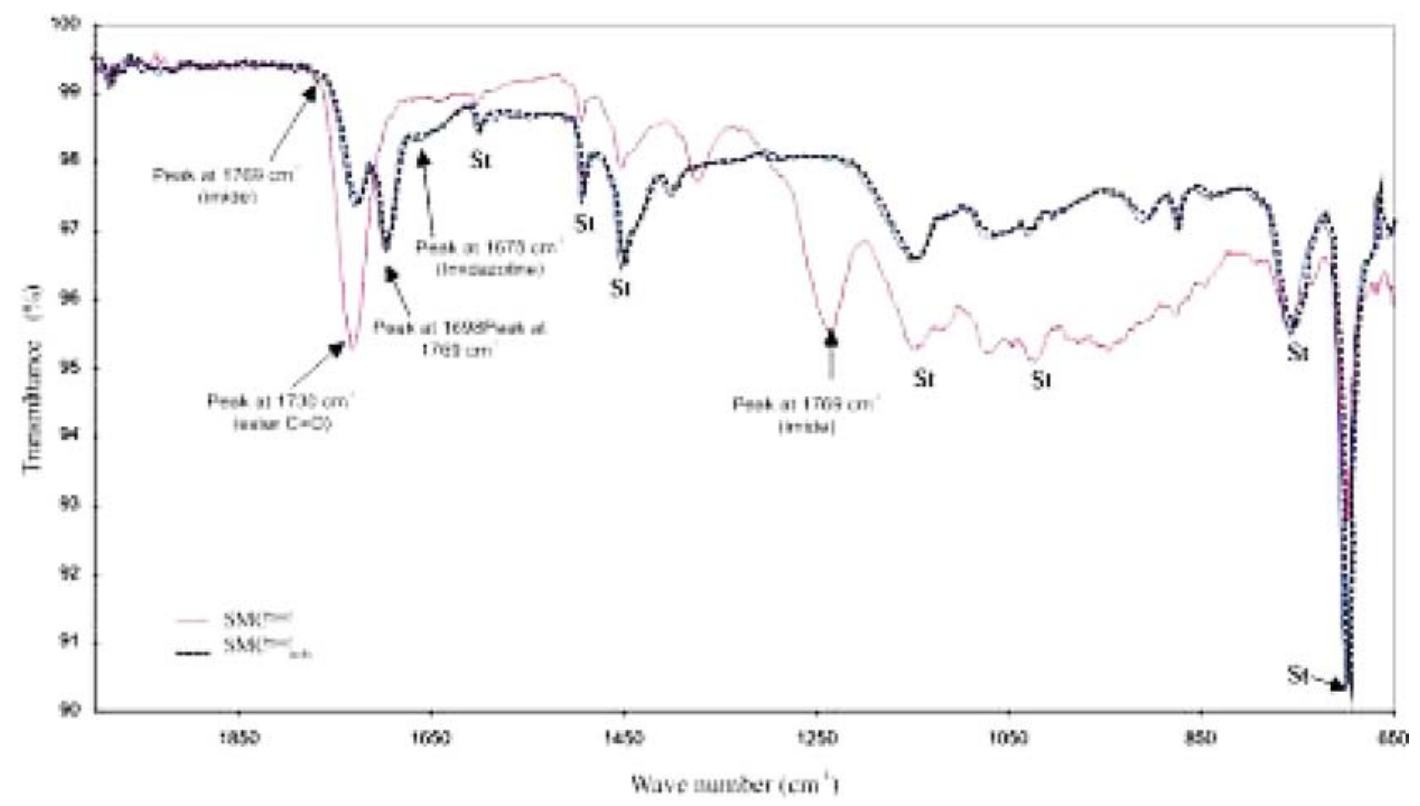

Figure 5 IRTF spectra of the SMC ${ }^{\text {mod }}$ and of the $\mathrm{SMC}^{\text {mod }}$ solvolysed by DETA during $3 \mathrm{~h}$ at $200^{\circ} \mathrm{C}$. 


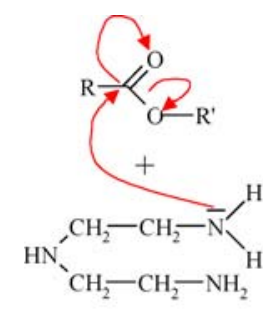<smiles>CCCCCCO</smiles><smiles>[R]C(=O)NCCNCC[NH-]</smiles><smiles>[R]C1=NCCN1CN</smiles>

Scheme 3 Proposed mechanism for the formation of imidazoline by reaction between ester and DETA [19]. fragments, which are expected to exhibit the greatest structural diversity, are driven off in a large part during the partial solvolysis and the remaining small-molecularweight fragments may be expected to cross polarize with low efficiency because of rapid molecular motions. Thus, the contributions of the large-molecular-weight fragments to the $\mathrm{CP} / \mathrm{MAS}{ }^{13} \mathrm{C}-\mathrm{NMR}$ spectra of the degradation products are easier to assign than FTIR spectra. Contributions of ${ }^{13} \mathrm{C}$ atoms are recorded separately by NMR but not by IR techniques. Dependence of CP/MAS ${ }^{13} \mathrm{C}$-NMR spectra on the crystallinity of the sample is much less important for IR. Furthermore, the assignments of ${ }^{13} \mathrm{C}$ resonances in $\mathrm{CP} / \mathrm{MAS}$ spectra to specific chemical functional groups can be confirmed by altering the cross-polarization pulse scheme to suppress the resonances of protonated carbons without affecting those of non-protonated carbons [21].

Based on the FTIR results, chain scissions of the $\mathrm{SMC}_{\text {solv }}^{\text {mod }}$ composite were taken into account. Therefore, the assumption of the main degradation mechanism was consistent with ester degradation, the key peaks to examine in ${ }^{13} \mathrm{C}$ NMR would be those associated with the ester. The interesting ranges on the spectra are 30-50 ppm (aliphatic groups), 60-80 ppm (alcohol and ether groups), 120-150 ppm (aryl and vinyl groups) and 160-180 ppm (carbonyl groups) [22]. The more intense

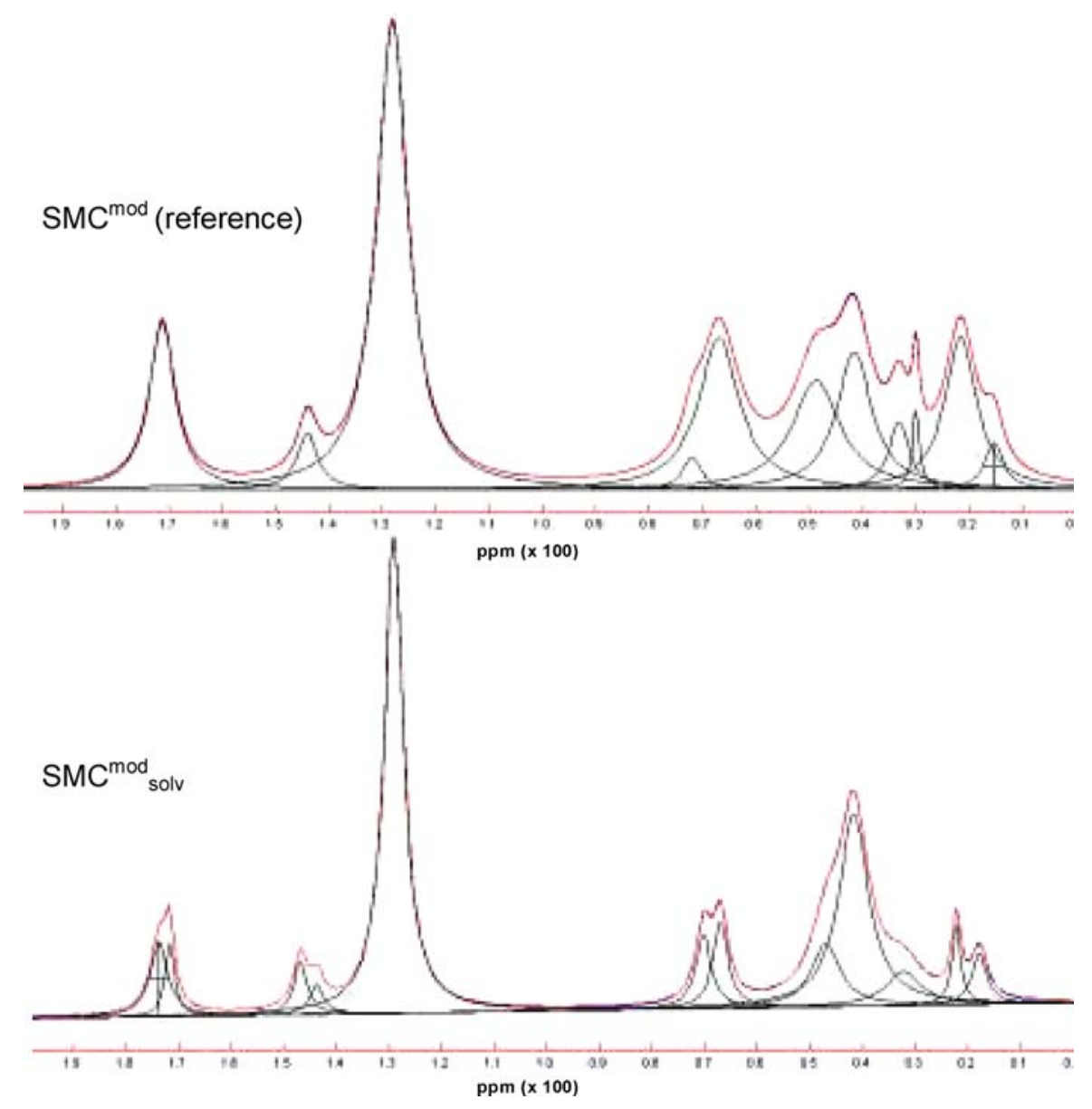

Figure 6 Qualitative ${ }^{13} \mathrm{C}$ NMR spectra of the initial and solvolysed SMC ${ }^{\text {mod }}$ and the deconvolution of these spectra. 
peak at $128 \mathrm{ppm}$ could correspond to the aryl groups from vinylic cross linkages within the SMC. As regards the initial SMC ${ }^{\text {mod }}$ (reference), the most interesting peaks correspond to the tertiary carbon atom adjacent to the ester linkage (32, 41 and $49 \mathrm{ppm})$. The existence of a possible chemical bonding between $\mathrm{SMC}^{\text {mod }}$ and DETA can be detected by a change in chemical shift of the carbons within this zone. Actually, as regards the $\mathrm{SMC}_{\text {solv }}^{\text {mod }}$ sample, the enhancement of the carbon peak at $32 \mathrm{ppm}$, in comparison with the reference $\mathrm{SMC}^{\mathrm{mod}}$, and the increase of the peak at $41 \mathrm{ppm}$ with a loss of the intensity of the peak at $49 \mathrm{ppm}$, could be ascertained as the chemical imidation link. Two peaks at 32 and $41 \mathrm{ppm}$ and the related upfield line broadening suggest that chemical bonding has occurred between DETA and SMC ${ }^{\text {mod }}$ ester groups. Moreover, between 60 and $200 \mathrm{ppm}$, for the chemically treated sample, the decrease of those peaks in relative intensity (68 ppm-145 ppm-171 ppm), indicates that a chemical change has occurred for those carbon atoms. Also, several new peaks appeared, in particular those located at $147 \mathrm{ppm}$ and $174 \mathrm{ppm}$. The peak at $147 \mathrm{ppm}$ corresponds to alkene moieties, and the peak at $174 \mathrm{ppm}$ corresponds to an amid imide moiety. Whereas the relative intensities of the peaks at 68 and $145 \mathrm{ppm}$ decrease with increasing chemical treatment, the relative intensity of the peak at $70 \mathrm{ppm}$ (alcohol groups) increases with this treatment. Based on this observation, it seems obvious that the ester linkage has been cleaved to form other components, namely alkenes and amid or imide.

The NMR and FTIR data again suggest that the $\mathrm{SMC}^{\text {mod }}$ is mainly degraded in a similar way than this of ester degradation, giving the imide amid chemical bonding expected. A general decomposition mechanism of the $\mathrm{SMC}^{\text {mod }}$ is shown in Scheme 4.

\subsection{Composites properties}

\subsubsection{Characterization of fibres length}

The glass fibre length distributions were determined after injection moulding and presented in Table IV.

The glass fibres length distribution is narrower for the recycled materials $\mathrm{SMC}^{\text {mod }}$ and $\mathrm{SMC}_{\text {solv }}^{\text {mod }}$ in the comparison with fibres in industrial composites. The chemical treatment of the $\mathrm{SMC}^{\text {mod }}$ does not influence the fibres length. These data seem indicate that the glass fibres seemed not too damaged by the global process, including shredding and dissolution steps.

It is very interesting to notice that long glass fibres could avoid the propagation of cracks which leading to the

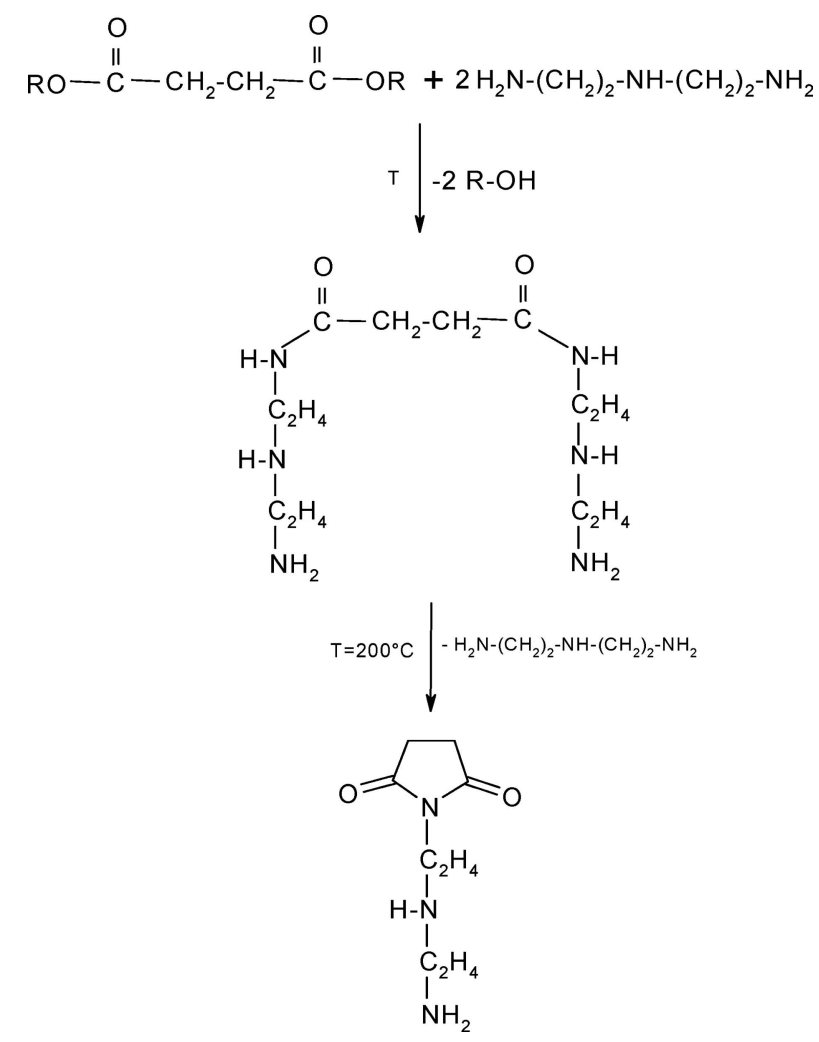

Scheme 4 Main chemical mechanism of solvolysis of SMC ${ }^{\text {mod }}$ with DETA [6].

failure of the future composite [23]. Glass fibres length distribution and average length have an influence on the mechanical properties of composites, because the fibre ends are particular sites for stress concentration where initiation and propagation of interfacial cracks can occur, leading to tensile failure. The stress transfer between fibre and the matrix is also related to the ability of glass fibres to work as reinforcements. According to Cox's model, the critical fibre length regarding reinforcement is between 200 and $500 \mu \mathrm{m}$ [24]. Consequently, fibres length distribution, for $\mathrm{SMC}^{\mathrm{mod}}$ and $\mathrm{SMC}_{\text {solv }}^{\text {mod }}$ obtained, allows to fully reinforce the composite.

\subsubsection{Mechanical properties}

Elastic modulus, tensile and impact strength of all the polypropylene-based composites are presented on Fig. 7. The error bars show the standard deviation.

$\mathrm{SMC}_{\text {solv }}^{\text {mod }}$ exhibits the better impact properties. This could be explained by the chemical link existing between modified matrix and solvolysed reinforcement. Actually,

TABLE IV Glass fibres distribution after incorporation into $\mathrm{PP} / \mathrm{PP}_{\text {gma }}$ matrix by injection process

\begin{tabular}{|c|c|c|c|c|}
\hline Distribution of glass fibre in $\mathrm{PP} / \mathrm{PP}_{\text {gma }}$ & Virgin glass fibres & $\mathrm{SMC}^{\bmod }$ & $\mathrm{SMC}_{\text {solv }}^{\text {mod }}$ & T401 filler (industrial process) \\
\hline Average length in number $(\mu \mathrm{m})$ & 740 & 410 & 400 & 200 \\
\hline Average length in length $(\mu \mathrm{m})$ & 890 & 430 & 430 & 250 \\
\hline Dispersity (\%) & 20 & 5 & 6 & 25 \\
\hline
\end{tabular}




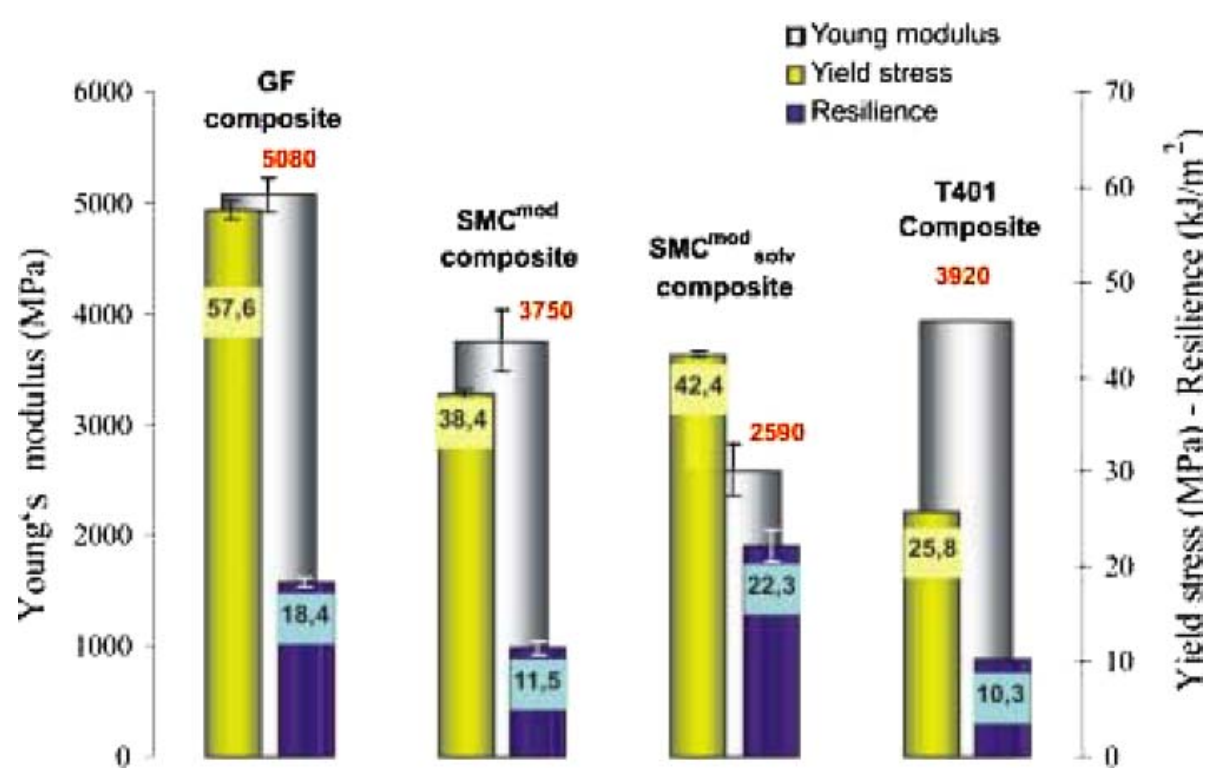

Figure 7 Mechanical properties of polypropylene-polypropylene grafted maleic anhydride based composites with an overall rate of glass fibres of $20 \%$ w/w.

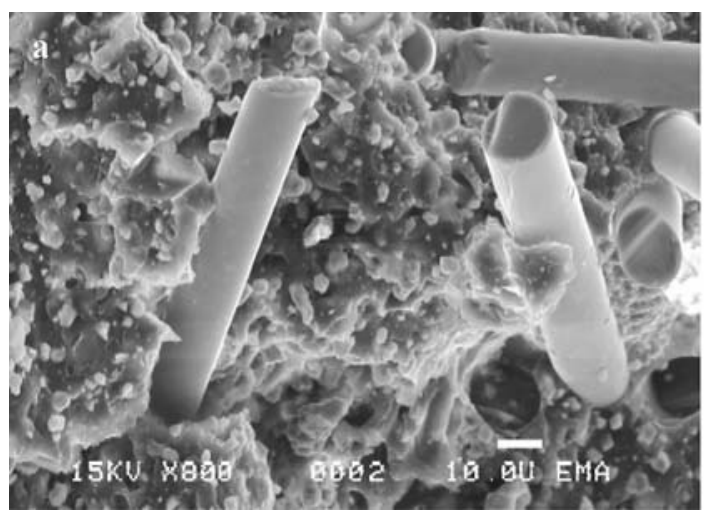

Figure 8 (a) $\mathrm{SMC}^{\text {mod }}$ fibres composites. (b) $\mathrm{SMC}_{\text {solv }}^{\text {mod }}$ fibres composites.

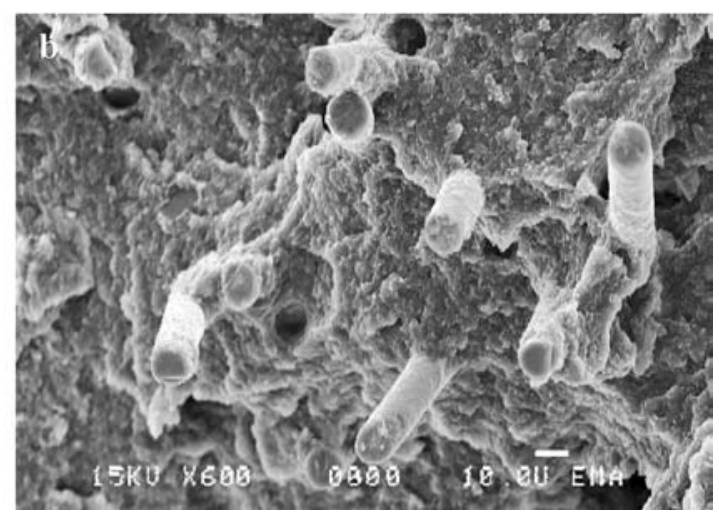<smiles>[Z]C(C)C1C(=O)[OH+]C(=O)C1CC</smiles><smiles>CCC1C(=O)N([R]N2C(=O)C(CC)C(C(C)C)C2=O)C(=O)C1C(C)C</smiles>

Scheme 5 Linkage reaction between matrix and reinforcing fillers.

Fig. 8 shows the difference of adhesion between matrix and $\mathrm{SMC}^{\text {mod }}$ and $\mathrm{SMC}_{\text {solv }}^{\text {mod }}$ composites.

$\mathrm{SMC}_{\text {solv }}^{\text {mod }}$ fibres (Fig. 8) are strongly embedded the matrix, conversely to $\mathrm{SMC}^{\text {mod }}$ fibres where smooth fibres can be observed.

Therefore, $\mathrm{SMC}_{\text {solv }}^{\text {mod }}$ should reduce the local stress concentration, which is not the case for the unmodified SMC composites (T401 and SMC ${ }^{\text {mod }}$ ) [25].

An increase in the tensile strength is observed on the Fig. 7 for $\mathrm{SMC}_{\text {solv }}^{\text {mod }}$ composite in comparison with $\mathrm{SMC}^{\mathrm{mod}}$ and T401 fibres. Such improvement ascribes to the presence of surface agent grafted on the $\mathrm{SMC}_{\text {solv }}^{\text {mod }}$ fillers and on the $\mathrm{PP}_{\text {gma }}$ present in the polymer matrix; the PP function- alized matrix could then react/interact readily with amine functions present on the polyester bulks from $\mathrm{SMC}_{\text {solv }}^{\text {mod }}$. A thoroughly succinimide formation created between reinforcing filler and modified matrix can result, entailing an increase of the interface and an improvement of the intrinsic mechanical properties. The linkage reaction is described by the following chemical equation (Scheme 5) [27].

Moreover, improvement in properties may also be attributed to adhesion enhancement between grafted PP and glass fibres slightly embedded in residual polyester functionalised by partial solvolysis. The same imidation reaction can occur between the amines on the glass fibres and 
the anhydrides from modified polypropylene matrix. To that may be added a poor adhesion between anhydrides and calcium carbonate present in the final composite based $\mathrm{SMC}_{\text {solv }}^{\text {mod }}$, because of a low amount of ionic interactions in the $\mathrm{SMC}^{\mathrm{mod}}$.

A strong improvement for $\mathrm{SMC}_{\text {solv }}^{\text {mod }}$ composite properties is observed in comparison with these of the industrial T401 composite. Chemical adhesion seems to be responsible of this rise, since anhydride functions are not present on the T401 polyester surface.

Compared to the PP reinforced with commercial glass fibres, $\mathrm{SMC}_{\text {solv }}^{\text {mod }}$ composite present lower mechanical properties. This can be ascribed to a strong degradation of the polyester network of SMC ${ }^{\text {mod }}$ due to a too drastic chemical attack of the ester link by the DETA. Furthermore, a plasticization could be induced by this chemical interfacial agent that could be present of the matrix in excess. This can be confirmed, according to the infrared spectrum, by the presence of a strong and large peak at $1700 \mathrm{~cm}^{-1}$ resulting from the amid imide formation and by the decrease of the ester peak at $1730 \mathrm{~cm}^{-1}$.

\section{Conclusion}

A partial solvolysis recycling process has been developed aiming to maximize mechanical properties of reinforcing fraction of SMC waste/PP-PP grafted maleic anhydride $\left(\mathrm{PP}_{\text {gma }}\right)$ composites.

At first, SMC waste is shredded and an increase of the reinforcing fraction is achieved by dissolving the calcium carbonate. Secondly, this fraction (SMC ${ }^{\mathrm{mod}}$ ) is functionalised by a interfacial chemical agent (triamine DETA) to modify its surface $\left(\mathrm{SMC}_{\text {solv }}^{\text {mod }}\right)$. This entails a chemical degradation by partial solvolysis, which is found to be consistent with ester modification mechanisms leading to an increase in the interfacial adhesion. As a matter of fact, the labile ester linkage is cleaved at $200^{\circ} \mathrm{C}$ during $3 \mathrm{~h}$, causing a breakdown of the polymer network leading to imide functions (succinimide).

Actually, the present experimental results have confirmed earlier works [26], reporting on the one hand that a reaction between anhydride and amine functions and, on the other hand, ester and amine functions could succeed to create a chemical bonding at the solid interface between reinforcing filler/interfacial agent/matrix.

It was also highlighted that the chemical effects of compatibilizers and the processing conditions are connected. Moreover, it was shown that a link is formed between SMC $^{\text {mod }}$ and DETA side and between maleic anhydride from $\mathrm{PP}-\mathrm{PP}_{\mathrm{gma}}$ and $\mathrm{SMC}_{\text {solv }}^{\text {mod }}$ created by the amine end-ofchains. An increase of the mechanical properties of the final composite is thereby resulting. These interfacial reactions have been characterized by infrared spectroscopy, microscopy and NMR analysis that allowed ascertaining amid or imide linkage. Further developments concern the optimisation of the degradation of SMC polyester process before incorporation in PP-PP gma $_{\text {a }}$ to avoid loss of stiffness for the $\mathrm{SMC}_{\text {solv }}^{\mathrm{mod}}$ composites.

\section{Acknowledgment}

The authors would like to thank the C.R.M.H.T.C.N.R.S. UPR 4212 of Orléans La Source (France), and more particularly, Dr. Dominique Massiot and Dr. Pierre Florian, for their support and availability concerning the use of the different NMR devices and the studies and interpretations of the CP/MAS ${ }^{13} \mathrm{C}$ and ${ }^{1} \mathrm{H}-\mathrm{NMR}$ spectra. The authors would want also to express their gratitude to Dr. M. Bartholin from the L.M.O.P.S.-C.N.R.S. UMR 5041 and to Mr. Dessalces from the S.C.A.-C.N.R.S. UPR 59, for their help about FTIR characterization of imidazoline.

\section{References}

1. M. LE TOULLEC, Industrie et Techniques 61 (1995) 756.

2. J. N. REYGROBELLET, J. M. LOPEZ-CUESTA and A. CRESPY, "Conference of Composite Materials" (ICCM 12, Paris, 1999).

3. J. N. REYGRobellet, PhD Thesis, Université Montpellier II, France (2000).

4. C. E. KOUPARITSAS, C. N. KARTALIS, P. C. VARELIDIS, C. J. TSENOGLOU and C. D. PAPASPYRIDES, Polym. Comp. 23(4) (2002) 682.

5. C. E. BREAM and P. R. HORNSB Y, J.Mater. Sci.36(2001) 2965.

6. H. Winter, H. A. M. MOSTERT and G. PAAS, J. Appl. Polym. Sci. 57 (1995) 1409.

7. M. VAllÉE, G. TERSAC, N. DESTAis-ORVOEN and G. DURAND, Ind. Eng. Chem. Res. 43 (2004) 317.

8. D. PERRIN, A. BERGERET, E. LEROY, L. CLERC and J.-M. LOPEZ-CUESTA, Compos. Sci. Technology, in progress (2005).

9. G. TESORO and Y. WU, Adv. Polym. Techn. 12(2) (1993) 185.

10. S. KUBOTA, A. ITO and H. MiYAmoto, US Patent 5776989 (1998).

11. T. A. TUFTS, C. C. TSAI and S. HUPP, WO Patent 94/25517 (1994).

12. C. M. TAI, T. GOTANDA and K. TSUDA, European Patent 1085 044 (2001).

13. H. TANAZAWA, T. HIROHATA and R. NISHIMURA, US Patent 5,733,942 (1998).

14. "Unsaturated polyesters, Encyclopedia of Polym. Sci. and Technology" (Interscience Publishers, 1969) Vol. 11.

15. S. ZHEN, L. ZHENG and B. YINJUAN, Science in China (Series B) 43(1) (2000) 69.

16. H. S. MANNHEIMER, US Patent 3,408,361 (1967).

17. D. PERRIN, E. LEROY, L. CLERC, A. BERGERET and J.-M. LOPEZ-CUES TA, Macromolecular Symposia 221 (2005) 227.

18. J. R. KENNERLY, R. M. KELLY, N. J. FENWICK, S. J. PICKERING and C. D. RUDD, Composites: Part A 29 (1998) 839.

19. L. J. BELLAMY, "The Infrared Spectra of Complex Molecules" (Chapman et Hall, 1995).

20. MARK, BIKALES, OVERBERGER and MENGES, Encyclopaedia Polym. Sci. Eng. 11, 476.

21. T. P. HUIJGEN, H. ANGAD GAUR, T. L. WEEDING, L. W. JENNESKENS, H. E. C. SCHUURS, W. G. B. HUYSMANS and W. S. VEEMAN, Macromolecules 23 (1990) 3063.

22. J.-S. CHEN, C. K. OBER and M. D. POLIKS, Polymer 43 (2001) 131.

23. A. G. PEDROSO, L. H. I. MEI, J. A. M. AGNELli and D. S. ROS A, Polym. Testing 18 (1999) 211.

24. H. L. COX, J. Appl. Phys. 3 (1952) 72.

25. J. HARTIKAINEN, P. HINE, J. S. SZABO, M. LINDNER, T. HARMiA, R. A. DUCKETT and K. FRIEDriCH, Comp. Sci. Techn. 65 (2005) 257.

26. J. ROEDER, R. V. B. OLIVEIRA, M. C. GONÇALVES, V. SOLDI and A. T. N. PIRES, Polym. Testing 21 (2002) 815. 